\title{
Transcriptional responses of Leishmania (Leishmania) amazonensis in the presence of trivalent sodium stibogluconate
}

\author{
Luz H. Patino ${ }^{1}$, Carlos Muskus ${ }^{2}$ and Juan David Ramírez ${ }^{1 *}$ (1)
}

\begin{abstract}
Background: In the last decade, resistance to antimonials has become a serious problem due to the emergence of drug-resistant strains. Therefore, understanding the mechanisms used by Leishmania parasites to survive under drug pressure is essential, particularly for species of medical-veterinary importance such as L. amazonensis.
\end{abstract}

Methods: Here, we used RNA-seq technology to analyse transcriptome profiles and identify global changes in gene expression between antimony-resistant and -sensitive L. amazonensis promastigotes.

Results: A total of 723 differentially expressed genes were identified between resistant and sensitive lines. Comparative transcriptomic analysis revealed that genes encoding proteins involved in metabolism (fatty acids) and stress response, as well as those associated with antimony resistance in other Leishmania species, were upregulated in the antimony-resistant line. Most importantly, we observed upregulation of genes encoding autophagy proteins, suggesting that in the presence of trivalent stibogluconate (S $b^{\text {III })}$ L. amazonensis can activate these genes either as a survival strategy or to induce cell death, as has been observed in other parasites.

Conclusions: This work identified global transcriptomic changes in an in vitro-adapted strain in response to Sb"II. Our results provide relevant information to continue understanding the mechanism used by parasites of the subgenus Leishmania (L. amazonensis) to generate an antimony-resistant phenotype.

Keywords: Resistance, Diffuse leishmaniasis, DEG, Hierarchical cluster analysis (HCA), Principal components analysis (PCA), Transcript

\section{Background}

Leishmaniasis is a complex of tropical diseases caused by protozoan parasites of the genus Leishmania, characterised by a broad spectrum of clinical manifestations that have been classified into five categories: localised cutaneous leishmaniasis (CL); diffuse CL (DCL); disseminated CL (DL); mucocutaneous leishmaniasis (MCL); and visceral leishmaniasis (VL). Over 30 Leishmania species have been identified to date, and classified into four subgenera: Leishmania (Leishmania), Leishmania (Viannia),

\footnotetext{
*Correspondence: juand.ramirez@urosario.edu.co

${ }^{1}$ Grupo de Investigaciones Microbiológicas-UR (GIMUR), Programa de Biología, Facultad de Ciencias Naturales y Matemáticas, Universidad del Rosario, Bogotá, Colombia

Full list of author information is available at the end of the article
}

Leishmania (Sauroleishmania) and Leishmania (Mundinia) $[1,2]$. Of the species belonging to subgenus Leishmania, L. amazonensis has particular clinical and epidemiological importance, especially in Latin America. Leishmania amazonensis is the main etiological agent of DCL, is implicated in borderline disseminated cutaneous leishmaniasis [3] and is responsible for $8 \%$ and $3 \%$ of $\mathrm{CL}$ cases in Brazil and Colombia, respectively [4, 5]. Additionally, several studies have identified $L$. amazonensis as a causative agent of VL in humans and animals (canines and felines), demonstrating its importance in both clinical and veterinary medicine [6-9].

To date, and in the absence of an available vaccine, chemotherapy is the only option for treatment of leishmaniasis. Although several different drugs are available, antimonials (e.g. sodium stibogluconate and meglumine 
antimoniate) remain standard treatment and the drugs of choice for treatment of all forms of leishmaniasis in different endemic areas (particularly Latin American). However, in the last decade there has been a largescale increase in therapeutic failure of antimonials [10]. Although the incidence of therapeutic failure in patients infected with $L$. amazonensis is unclear, a percentage of patients who subsequently develop DCL (caused by a failure of the immune response) show a poor response to antimonials [11].

Numerous factors impact the final therapeutic outcome of antimonial treatment [12], with factors associated with the parasite itself. Several studies have focused on determining the mechanisms used by the parasite to survive under drug pressure using next-generation sequencing techniques [genomics, transcriptomics (RNA-seq), proteomics and metabolomics]. Some of these studies, mainly using strains of $L$. donovani, L. major and $L$. infantum, have demonstrated that, under drug pressure, Leishmania uses several adaptative mechanisms to modulate the gene dosage of therapeutic targets or other determinants of resistance. Some of these mechanisms include the generation of episomal amplicons, changes in ploidy of the whole chromosome and/or generation of local gene copy number variation, production of single-nucleotide polymorphisms in drug targets or upregulating proteins that may play a role in intracellular survival [13-18].

Recently, RNA-seq technology has emerged as a powerful tool in the study of Leishmania species. It has been used to determine the transcriptomic profiles of different species of Leishmania (L. major, L. donovani, L. infantum, L. mexicana, L. amazonensis and L. braziliensis), expanding our knowledge about parasite biology and their interactions with vertebrate and invertebrates hosts [19-23]. In addition, RNA-seq has been used to study the transcriptomic response to different stress conditions, and to identify genes associated with resistance to antimonials, mainly in strains of the $L$. donovani complex $[15,24,25]$.

RNA-seq-based analyses have also been used in New World Leishmania species, including $L$. amazonensis, $L$. braziliensis and $L$. mexicana, to analyse transcriptional behaviour under specific conditions [20, 22, 26, 27]. However, none of these studies have focused on identifying transcriptional changes that occur in these parasites under stress conditions (such as drug pressure), as has been described for Old World Leishmania species. These data are particularly lacking for L. amazonensis, a species that is emerging as a pathogen of medical-veterinary importance in Latin America. Therefore, the purpose of this study was to conduct a comprehensive transcriptome profiling using RNA-seq to identify global changes in gene expression that occur in L. amazonensis in response to $\mathrm{Sb}^{\mathrm{III}}$ exposure, and to obtain a general picture of the mode of action in which this species regulates in vitro gene expression under drug pressure. Our results contribute to the understanding of in vitro $\mathrm{Sb}^{\mathrm{III}}$-resistance phenotypes and help to determine the global transcriptional effects of $\mathrm{Sb}^{\mathrm{III}}$. This is also the first report providing transcriptome data for L. amazonensis submitted to a specific drug pressure.

\section{Methods}

Culture conditions and development of drug-resistant $L$. amazonensis promastigotes

Promastigotes of L. amazonensis [obtained from one patient with clinical CL symptoms from Medellin (Colombia) and named UA301] sensitive to $\mathrm{Sb}^{\mathrm{III}}\left(\mathrm{Sb}^{\mathrm{III}}-\mathrm{S}\right)$ and resistant to $\mathrm{Sb}^{\mathrm{III}}\left(\mathrm{Sb}^{\mathrm{III}}-\mathrm{R}\right)$ were axenically maintained in RPMI 1640 medium from Sigma-Aldrich (St. Louis, MO, USA) supplemented with $10 \%(\mathrm{v} / \mathrm{v})$ heat inactivated fetal bovine serum from Thermo Fisher Scientific (Boston, MA, USA) and cultured at $26{ }^{\circ} \mathrm{C}$ with $5 \% \mathrm{CO}_{2}$. DNA extraction and subsequent species identification, which was performed by direct Sanger sequencing of the cytochrome b (cytb) and heat-shock protein (hsp70) gene fragments, was carried out as described by Ramirez et al. [5].

The $\mathrm{Sb}^{\mathrm{III}}$-resistant population, L. amazonensis (La$\mathrm{Sb}^{\mathrm{III}}-\mathrm{R}$ ) promastigotes were obtained from wild-type sensitive L. amazonensis ( $\mathrm{La}-\mathrm{Sb}^{\mathrm{III}}-\mathrm{S}$ ) via the continuous stepwise increase in drug pressure with $\mathrm{Sb}^{\mathrm{III}}$, as described previously [28], with slight modifications. The selection of resistant parasites was initiated in quadruplicates. Briefly, $10^{6}$ logarithmic-phase promastigotes were incubated with different concentrations of $\mathrm{Sb}^{\mathrm{III}}$. The drug concentration was increased in a stepwise process only when the drug-exposed parasites had a growth rate similar to that of the parental parasites. Selection rounds were performed successively with 2-fold increase with $1.0,2.0,4.0,8.0,16,32,64$ and $128 \mu \mathrm{g} / \mathrm{ml} \mathrm{Sb}{ }^{\mathrm{III}}$. This incrementation was continued until the maximum concentration of parasite growth. After this period, the $\mathrm{Sb}^{\mathrm{III}}$ - $\mathrm{R}$ line was maintained for 3 weeks at the final drug concentration. To verify that the observed drug-resistant phenotype was stable, we cultivated the $\mathrm{Sb}^{\mathrm{III}}$-resistant line for 4 weeks in the absence of $\mathrm{Sb}^{\mathrm{III}}$. The $\mathrm{Sb}^{\mathrm{III}}$-sensitive $L$. amazonensis was cultured in parallel, but without any drug pressure. At the end of this period, the susceptibility of the sensitive and resistant lines to $\mathrm{Sb}^{\mathrm{III}}$ was determined by calculating the $\mathrm{EC}_{50}$ in an MTT [3-(4,5-dimethylthiazol-2-yl)-2,5-diphenyltetrazolium bromide] colorimetric assay, as previously described [29]. The reduction of MTT to its insoluble form formazan was evaluated in a Tecan GENios Microplate Reader (Biotek, Winooski, VT, USA), with an emission of $570 \mathrm{~nm}$. The corresponding 
absorbance values were obtained from the spectrofluorometric reading and the $\mathrm{EC}_{50}$ was calculated using Graph Pad Prism v.5.0 software. The assays were performed three times in triplicate. Differences in the data were considered significant when the resistance index was $\geq 10$-fold different between the $\mathrm{Sb}^{\mathrm{III}}$-resistant and -sensitive lines. Once the parasites were selected $\left(\mathrm{Sb}^{\mathrm{III}}\right.$-resistant and sensitive), they were cloned from culture into 96-well plates containing RPMI medium supplemented, via limiting dilution as described previously [30].

\section{RNA isolation}

Approximately $1 \times 10^{6}$ promastigotes (sensitive and resistant to $\mathrm{Sb}^{\mathrm{III}}$ ) in the middle logarithmic growth phase were cultured and harvested by centrifugation. The resulting pellets were used to conduct the RNA extraction. Total RNA was extracted from four independent replicates (two technical and two biological replicates) of each $\mathrm{Sb}^{\mathrm{III}}$-resistant and -sensitive line, each originating from a separate culture. The RNA was extracted with the RNeasy Mini Kit (Qiagen, Hilden, Germany). The RNA concentrations were determined with a NanoDrop ND-1000 spectrophotometer (Thermo Fisher Scientific) and the quality and integrity with a 2100 Bioanalyzer system (Agilent Technologies, Santa Clara, CA, USA) according to the manufacturers' instructions.

\section{Transcriptome sequencing and data analysis}

The mRNA and cDNA library were prepared and sequenced with the HiSeq X-Ten system (Illumina, San Diego, CA, USA) by Novogene Bioinformatics Technology Co., Ltd, Beijing, China. Paired reads of 75 nucleotides were obtained for the mRNA libraries, whereas $2 \times 100$ bp length of reads were obtained for the cDNA libraries. Sequence quality metrics were assessed with FastQC (Illumina platform, PE 150, Q30 $\geq 80 \%$; 250$300 \mathrm{bp}$ insert cDNA library). Additionally, 20M raw reads/sample rRNA depletion was performed by poly(A) magnetic beads capture protocol, using Strand-specific TrueSeq RNA-seq Library Prep (Illumina), according to the manufacturer's instruction.

Reads were mapped to the $L$. mexicana reference genome (MHOM/GT/2001/U1103) obtained from TriTrypDB (www.tritrypdb.org) using Smalt v.7.4 (http:// www.sanger.ac.uk/science/tools/smalt-0). The $L$. mexicana genome was used as the L. amazonensis genome is not completely annotated. The amounts of each of the transcripts were quantified by assessing read depth, as described previously [31,32]. For differential expression analysis, STAR v.2.5.2 was used for mapping and read counting per gene with default parameters where multiply mapped reads were marked and ignored. DEseq2 v.1.18.1 was then used to normalize the read counts and evaluate the statistical significance of differentially expressed genes. Here the following criteria were used: a fold-change cut-off of $\geq 2$ and a Benjamini-Hochberg adjusted $P$-value $<0.05$. The percentage of differentially expressed genes (DEGs) per chromosome was defined as follows: (number of differentially expressed genes per chromosome)/(number of total genes per chromosome) $\times 100$.

In the initial data exploration, we constructed a principal components analysis (PCA) and hierarchical cluster analysis (HCA) to test whether both conditions (sensitive and resistant) could be clustered separately. The PCA was performed in $\mathrm{R}$ directly and was based on the variant stabilized count of each sample. The HCA was performed by applying the Euclidean distance measure and Ward's algorithm. The Euclidean distance was calculated over the rlog-transformed count using DESeq 2 and plotted using the pHeatmap $\mathrm{R}$ package (https://cran.r-proje ct.org/). The four replicates of each condition ( $\left(\mathrm{La}-\mathrm{Sb}^{\mathrm{III}}-\mathrm{S}\right.$ and $\mathrm{La}-\mathrm{Sb}^{\mathrm{III}}-\mathrm{R}$ ) were used.

Gene Ontology enrichment analyses were performed using Tritrypdb tools (http://tritrypdb.org) with Fisher's exact test used to maintain the FDR below 0.05 . The GO terms were submitted to REVIGO, which is a web server that takes long lists of GO terms and summarizes them in categories and clusters of differentially expressed genes by removing redundant entries [33]. Finally, a Venn diagram was constructed using an online program provided by the Bioinformatics and Evolutionary Genomics group of the University of Gent and the VIB institute (http:// bioinformatics.psb.ugent.be/webtools/Venn/).

\section{Results}

\section{Induction of Sb"' resistance in L. amazonensis line}

Initially, we selected in vitro populations of L. amazonensis that were resistant to $\mathrm{Sb}^{\mathrm{III}}$. In the selection dynamics, two replicates did not survive; the third $(4.0 \mu \mathrm{g} / \mathrm{ml}$ $\left.\mathrm{Sb}^{\mathrm{III}}\right)$ and fourth $\left(8.0 \mu \mathrm{g} / \mathrm{ml} \mathrm{Sb}{ }^{\mathrm{III}}\right)$ rounds of selection and two replicates were successfully selected to survive to seven rounds $(64 \mu \mathrm{g} / \mathrm{ml})$. At the highest $\mathrm{Sb}^{\mathrm{III}}$ concentration $(128 \mu \mathrm{g} / \mathrm{ml})$, the parasites died (see Additional file 1: Figure S1). Likewise, when we evaluated the stability of the resistance phenotype $\left(64 \mu \mathrm{g} / \mathrm{ml} \mathrm{Sb}{ }^{\mathrm{III}}\right.$ for 4 weeks), we observed that the resistance index of each line remained, suggesting that the in vitro selected drug resistance phenotype was stable.

\section{Differentially expressed transcripts between the $\mathrm{Sb}^{\text {III-}}$-resistant and -sensitive L. amazonensis lines}

As a first data exploration of the variation in our dataset, we performed a principal component analysis (PCA) and hierarchical cluster analysis (HCA). The results observed 


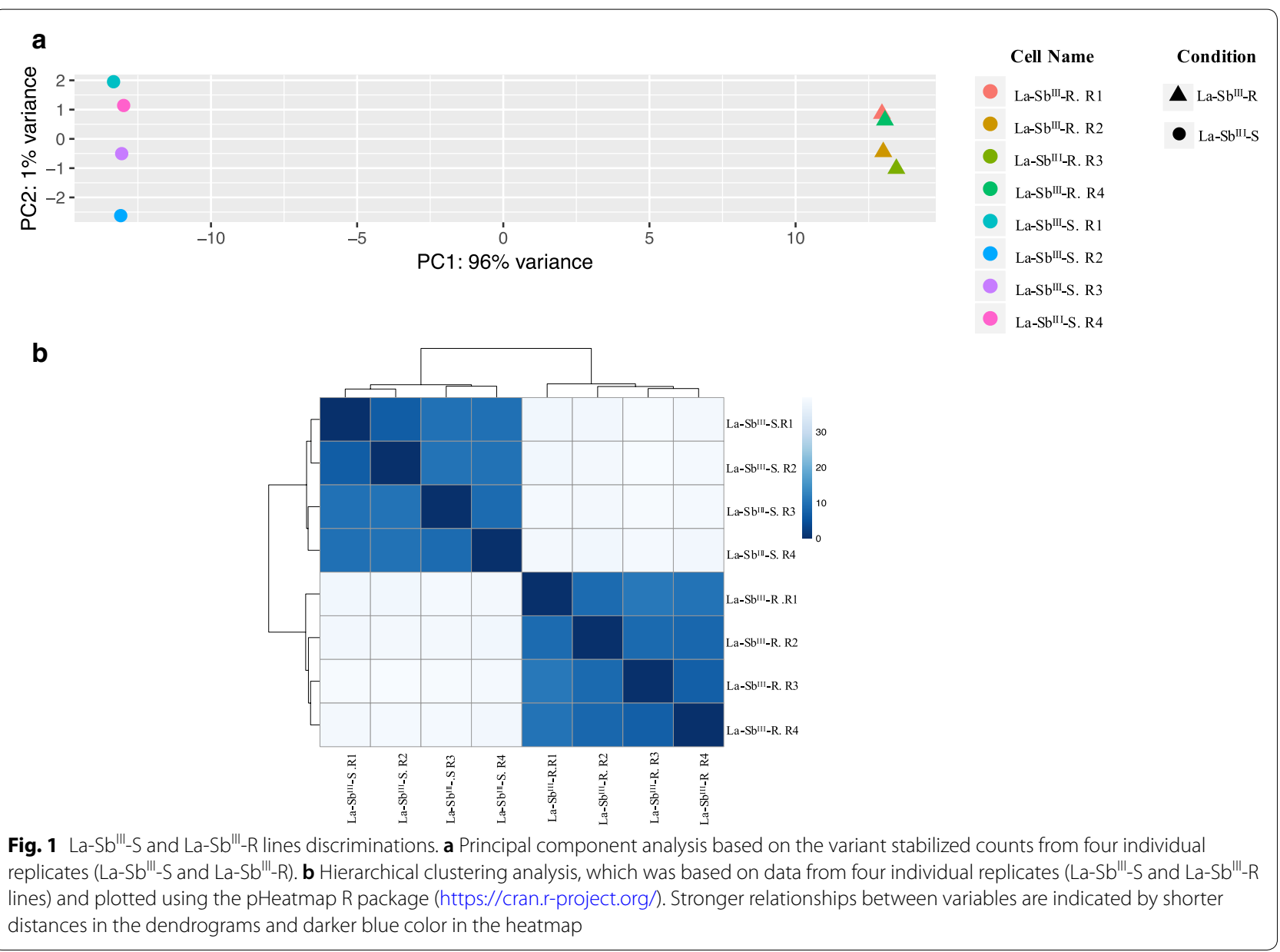

in the PCA showed that the first principal component explained $96 \%$ of the total variation in our experimental lines and clearly separated the $\mathrm{La}-\mathrm{Sb}^{\mathrm{III}}-\mathrm{S}$ from $\mathrm{La}-\mathrm{Sb}^{\mathrm{III}}-\mathrm{R}$ lines (Fig. 1a). Likewise, in the HCA, when Euclidean distance between samples was computed and used to create a heatmap colour image and dendrogram depicting the relatedness between samples, a clear separation between resistant and sensitive lines was observed (Fig. 1b).

Later, we evaluated the expression profile of L. amazonensis under drug pressure, performing differential gene expression analysis of $\mathrm{Sb}^{\mathrm{III}}$-sensitive and $\mathrm{Sb}^{\mathrm{III}}$-resistant L. amazonensis lines ( $\mathrm{La}_{-} \mathrm{Sb}^{\mathrm{III}}-\mathrm{S}$ and $\mathrm{La}-\mathrm{Sb}^{\mathrm{III}}-\mathrm{R}$, respectively). We identified a total of 723 genes that were differentially expressed between the two lines ( $P$-value cut-off of $<0.05$ and fold-change difference $\geq 2$ ), 330 upregulated and 393 downregulated in the $\mathrm{La}-\mathrm{Sb}^{\mathrm{III}}$-R line (see Additional file 2: Table S1). Additionally, these genes were visualised using an MA plot showing the relationship between mean expression and fold-change for each gene (Fig. 2). Of the 723 genes that were significantly up/ downregulated in the $\mathrm{La}-\mathrm{Sb}^{\mathrm{III}}$-R line, 46\% (335/723) were annotated as hypothetical proteins, with the remaining gene products associated with various biological functions in the parasite (surface proteins, virulence, metabolism, cell cycle, autophagy, cytoskeletal and stress response).

\section{Gene Ontology (GO) and Kyoto Encyclopedia of Genes and Genomes (KEGG) enrichment analysis of differentially expressed genes (DEGs)}

To better analyse the DEGs, we performed GO and KEGG enrichment-based analyses. The 723 DEGs were categorised into three functional GO groups: biological process; molecular function; and cellular component. Within the biological processes GO group, the genes upregulated in the $\mathrm{La}-\mathrm{Sb}^{\mathrm{III}}-\mathrm{R}$ line were mainly predicted to be involved in regulation of the cell cycle and organelle organisation but were also associated with stress response and divalent metal ion transport. However, the downregulated genes were involved in nucleotide biosynthesis and carbohydrate transport (Fig. 3a). For the molecular function group, genes upregulated in the La$\mathrm{Sb}^{\mathrm{III}}-\mathrm{R}$ line mainly encoded binding proteins and proteins with enzymatic activity, while the downregulated genes 


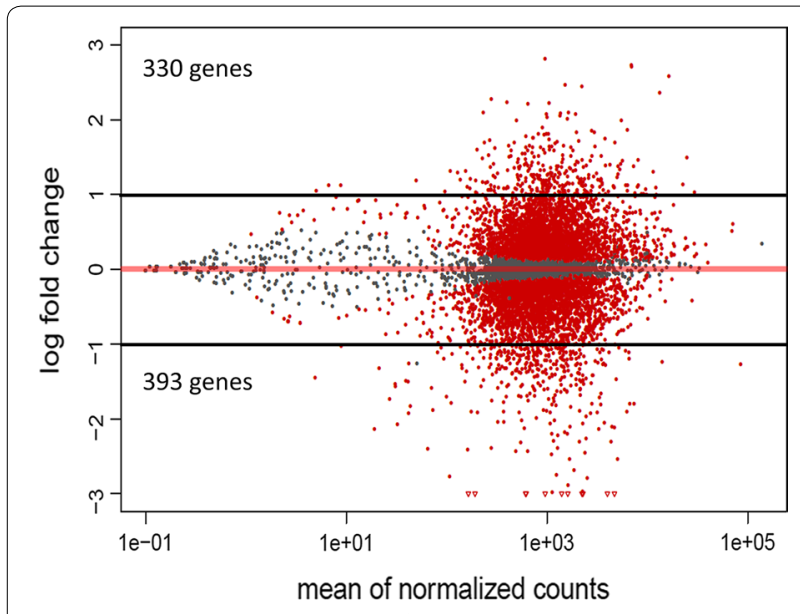

Fig. 2 Graphical representation of genes differentially expressed between $\mathrm{La}-\mathrm{Sb} b^{\mathrm{II}}-\mathrm{S}$ and $\mathrm{La}-\mathrm{Sb} \mathrm{b}^{\mathrm{II}}-\mathrm{R}$. The figure represents the MA plot constructed based on the DESeq2 results, showing the relationship between mean expression (normalised counts) and fold-change for each gene. Each point represents one gene. Gray dots indicate the genes that were not differentially expressed and the red dots, located above and below of black discontinuous lines (cut-off for the fold-change (log fold-change $>1$ and $<-1$ ), represent differentially expressed genes with abs $[\log 2(\mathrm{FC})]>1$ and an adjusted $P$-value $<0.01$, between La-Sb ${ }^{\text {III }}$-S and La-Sb ${ }^{\text {III }}-\mathrm{R}$ mainly encoded carbohydrate transporters and proteins with peptidase activity (Fig. 3b). Finally, within the cellular components group, the up- and downregulated genes in the La-Sb ${ }^{\mathrm{III}}-\mathrm{R}$ line encoded proteins localised mainly in the nuclear component and in the axoneme, respectively (Fig. 3c).

KEGG enrichment analysis revealed that genes upregulated in the La-Sb ${ }^{\mathrm{III}}-\mathrm{R}$ line were involved in pyrimidine metabolism, while the downregulated genes were involved in ubiquinone biosynthesis, glycine, serine and threonine metabolism, ascorbate and aldarate metabolism, drug metabolism-cytochrome P450 and glycosaminoglycan degradation (Fig. 4, Table 1).

\section{Surface molecules}

Thirteen transcripts encoding surface proteins were downregulated in the $\mathrm{La}-\mathrm{Sb}^{\mathrm{III}}-\mathrm{R}$ line compared with the $\mathrm{La}-\mathrm{Sb}^{\mathrm{III}}$-S line. Eight of these encoded surface antigenlike protein (PSA), four were expressed in tandem in the chromosome 4, two encoded proteophosphoglycan ppg3/ ppg1 and the remaining transcripts encoded lipophosphoglycan (LPG), surface membrane protein gp46-like and major surface protease gp63 (GP63, or leishmanolysin). The most strongly downregulated transcripts in the

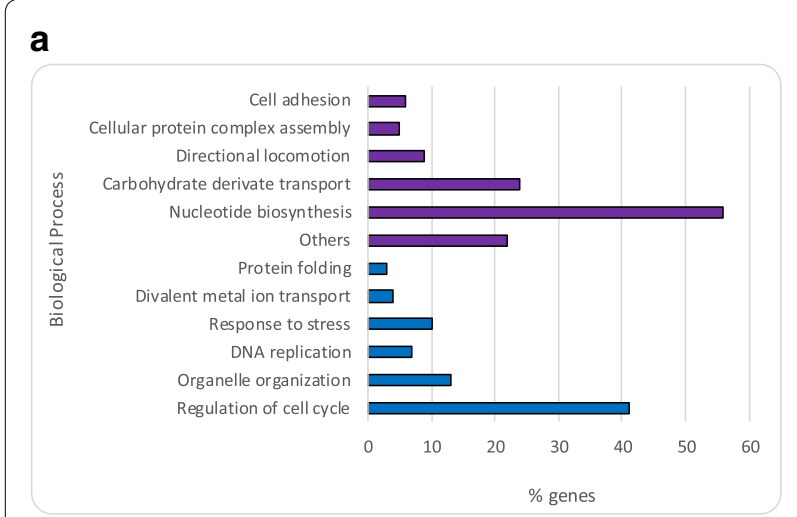

b

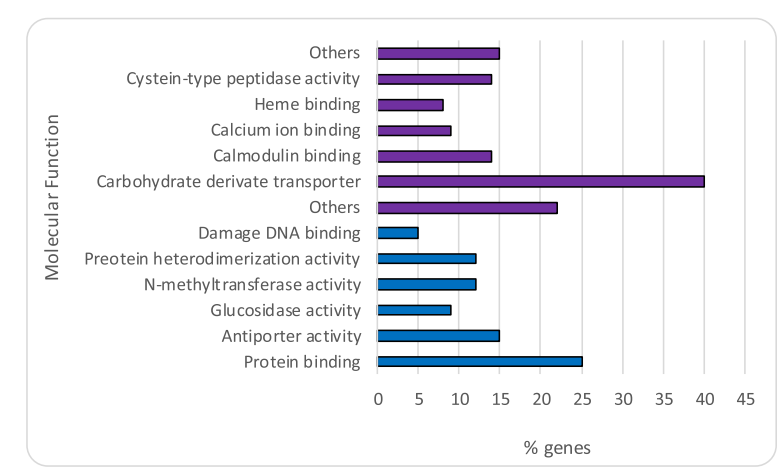

C

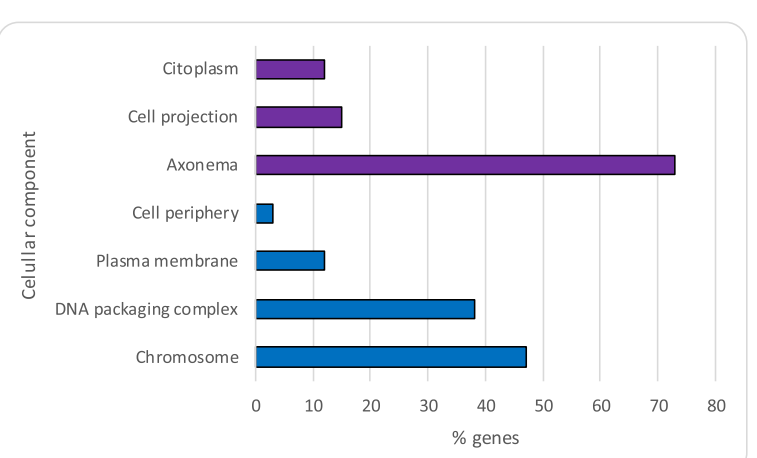

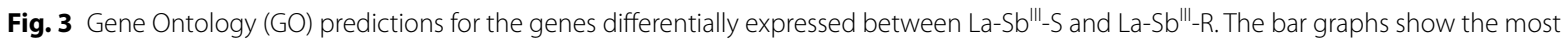
represented functions within three categories: biological process (a), molecular function (b) and cellular component (c). The blue and purple bars represent the up- and downregulation, respectively, of genes in the resistant line compared with the sensitive line 


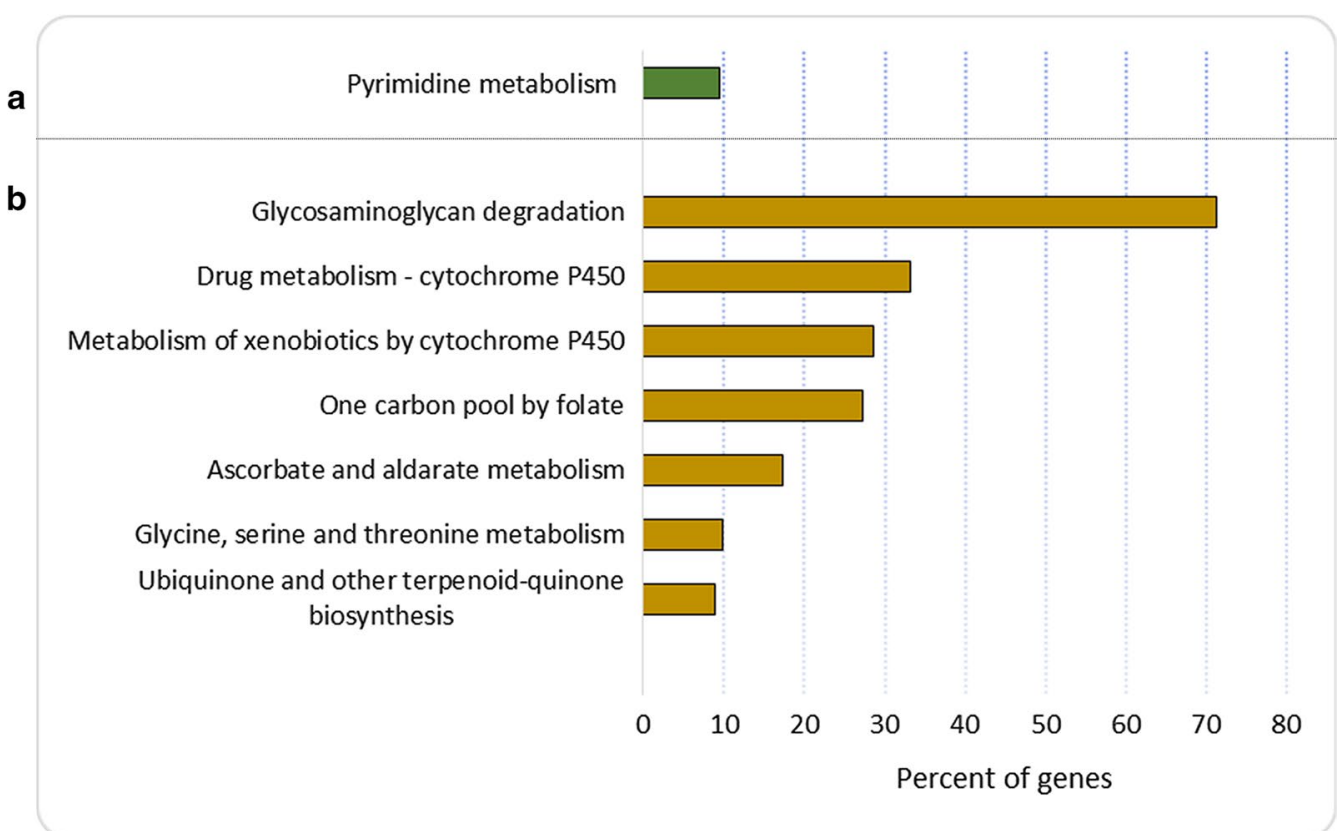

Fig. 4 Kyoto Encyclopedia of Genes and Genomes enrichment analysis for the genes differentially expressed between La-Sb ${ }^{\prime \prime \prime}-S$ and La-Sb $b^{\prime \prime \prime}-R$. The

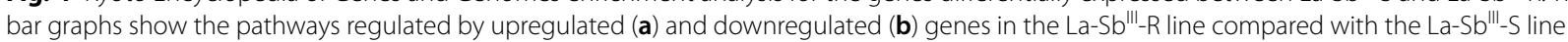

Table 1 KEGG enrichment analysis of the up- and downregulated genes in the La-Sb ${ }^{I I}$-R line

\begin{tabular}{|c|c|c|}
\hline Pathway ID & Map name & Genes \\
\hline \multicolumn{3}{|c|}{ Upregulated genes } \\
\hline ec00240 & Pyrimidine metabolism & $\begin{array}{l}\text { LmxM.13.1630, LmxM.18.1580, LmxM.21.1210, LmxM.23.0680, } \\
\text { LmxM.28.0890, LmxM.28.1420, LmxM.28.1430, LmxM.33.0010, } \\
\text { LmxM.34.1790 }\end{array}$ \\
\hline \multicolumn{3}{|c|}{ Downregulated genes } \\
\hline ec00130 & Ubiquinone and other terpenoid-quinone biosynthesis & $\begin{array}{l}\text { LmxM.05.1100, LmxM.34.0500, LmxM.34.0500a, LmxM.34.0520b, } \\
\text { LmxM.34.0540, LmxM.34.0550 }\end{array}$ \\
\hline ec00260 & Glycine, serine and threonine metabolism & $\begin{array}{l}\text { LmxM.10.0090, LmxM.14.1320, LmxM.29.2090, LmxM.32.0520, } \\
\text { LmxM.36.3800 }\end{array}$ \\
\hline ec00053 & Ascorbate and aldarate metabolism & $\begin{array}{l}\text { LmxM.10.0090, LmxM.18.0160, LmxM.26.0160, LmxM.32.0520, } \\
\text { LmxM.33.0010, LmxM.34.0500, LmxM.34.0500a, } \\
\text { LmxM.34.0520b, LmxM.34.0540, LmxM.34.0550 }\end{array}$ \\
\hline ec00670 & One carbon pool by folate & LmxM.14.1320, LmxM.36.3800, LmxM.36.6390 \\
\hline ec00980 & Metabolism of xenobiotics by cytochrome P450 & LmxM.29.2090, LmxM.32.0240 \\
\hline ec00982 & Drug metabolism - cytochrome P450 & LmxM.29.2090, LmxM.32.0240 \\
\hline ec00531 & Glycosaminoglycan degradation & $\begin{array}{l}\text { LmxM.34.0500, LmxM.34.0500a, LmxM.34.0520b, LmxM.34.0540, } \\
\text { LmxM.34.0550 }\end{array}$ \\
\hline
\end{tabular}

La-Sb ${ }^{\mathrm{III}}-\mathrm{R}$ line were homologous transcript described in L. mexicana, a close species related with L. amazonensis, LmxM.05.0900, LmxM.34.0500 and LmxM.28.0570, encoding PSA, proteophosphoglycan ppg3 and major surface protease gp63, respectively (Table 2). Despite mainly observing downregulation of surface molecules in the La-Sb ${ }^{\mathrm{III}}-\mathrm{R}$ line, five transcripts (LmxM.08.0720,
LmxM.08.0730, LmxM.08.0740, LmxM.28.1400 and LmxM.33.1920) encoding amastin-like surface protein were upregulated. Three of these transcripts were expressed in tandem from chromosome 8. 
Table 2 List of most highly differentially-expressed genes between the La-Sb ${ }^{\text {III }}-\mathrm{S}$ and La-Sb ${ }^{\text {III }}$-R lines ( $P$-value cut-off $<0.05$ and foldchange difference $\geq 2$ )

\begin{tabular}{|c|c|c|c|}
\hline Biological functions & Transcript & Product description & $\begin{array}{l}\log _{2} \text { fold- }- \\
\text { change } \\
(\mathrm{R} / \mathrm{S})\end{array}$ \\
\hline \multirow[t]{18}{*}{ Surface proteins } & LmxM.09.0580 & Surface antigen-like protein & -1.1603 \\
\hline & LmxM.05.1215 & Surface antigen-like protein & -1.2685 \\
\hline & LmxM.21.1170 & Surface antigen-like protein & -1.2882 \\
\hline & LmxM.04.0190 & Surface antigen-like protein & -1.8081 \\
\hline & LmxM.04.0210 & Surface antigen-like protein & -1.9894 \\
\hline & LmxM.04.0180 & Surface antigen-like protein & -2.0656 \\
\hline & LmxM.04.0200 & Surface antigen-like protein & -2.3355 \\
\hline & LmxM.05.0900 & Surface antigen-like protein & -3.7896 \\
\hline & LmxM.34.0550 & Proteophosphoglycan ppg1 & -1.5215 \\
\hline & LmxM.34.0500 & Proteophosphoglycan ppg3, putative & -3.2111 \\
\hline & LmxM.33.3120 & Lipophosphoglycan biosynthetic protein (lpg2) & -1.2312 \\
\hline & LmxM.30.1450 & Surface membrane protein gp46-like protein & -1.3431 \\
\hline & LmxM.28.0570 & Major surface protease gp63, putative & -3.0596 \\
\hline & LmxM.08.0730 & Amastin-like protein, putative & 1.0151 \\
\hline & LmxM.28.1400 & Amastin-like protein & 1.1033 \\
\hline & LmxM.08.0720 & Amastin-like protein, putative & 1.1165 \\
\hline & LmxM.08.0740 & Amastin-like protein, putative & 1.2047 \\
\hline & LmxM.33.1920 & Amastin-like surface protein, putative & 1.7594 \\
\hline \multirow[t]{18}{*}{ Metabolism } & Metabolite transporters & & \\
\hline & LmxM.10.0350 & Pteridine transporter $\mathrm{ft} 5$, putative & -1.0251 \\
\hline & LmxM.24.0360 & UDP-galactose transporter & -1.0742 \\
\hline & LmxM.15.1230 & Nucleoside transporter 1, putative & -1.4466 \\
\hline & LmxM.32.0290 & Glucose transporter/membrane transporter D2, putative & -1.5513 \\
\hline & LmxM.15.1240 & Nucleoside transporter 1, putative & -1.9139 \\
\hline & LmxM.30.0320 & Amino acid transporter, putative & -1.9548 \\
\hline & Glycolysis & & \\
\hline & LmxM.10.0510 & $\begin{array}{l}\text { Glycerol-3-phosphate dehydrogenase [NAD+], glycosomal/mito- } \\
\text { chondrial }\end{array}$ & -1.1530 \\
\hline & Proteolysis & & \\
\hline & LmxM.08.1080 & Cathepsin L-like protease, putative & -2.2280 \\
\hline & Fatty acid pathways & & \\
\hline & LmxM.30.2970 & Acetyl-CoA carboxylase & 1.0198 \\
\hline & LmxM.23.0710 & Acetyl-CoA synthetase, putative & 1.3180 \\
\hline & Other metabolic enzymes & & \\
\hline & LmxM.29.1940 & Succinyl-coa:3-ketoacid-coenzyme a transferase- like protein & -1.5541 \\
\hline & LmxM.26.1610 & Proline dehydrogenase, mitochondrial & 1.2112 \\
\hline & LmxM.27.0880 & 2-oxoglutarate dehydrogenase subunit, putative & 1.1954 \\
\hline
\end{tabular}


Table 2 (continued)

\begin{tabular}{|c|c|c|c|}
\hline Biological functions & Transcript & Product description & $\begin{array}{l}\log _{2} \text { fold- } \\
\text { change } \\
(\mathrm{R} / \mathrm{S})\end{array}$ \\
\hline \multirow[t]{17}{*}{ Cell cycle } & LmxM.20.0030 & Histone-lysine N-methyltransferase, $\mathrm{H} 3$ lysine- 76 specific & 2.4946 \\
\hline & LmxM.07.0025 & Histone-lysine $\mathrm{N}$-methyltransferase, putative & 2.4788 \\
\hline & LmxM.10.0990 & Histone H3 & 2.0457 \\
\hline & LmxM.10.0870 & Histone H3 & 1.8415 \\
\hline & LmxM.25.0920 & Histone RNA hairpin-binding protein & 1.5715 \\
\hline & LmxM.20.0050 & Histone chaperone ASF1A & 1.3835 \\
\hline & LmxM.36.0020 & Histone H4 & 1.2945 \\
\hline & LmxM.19.0050 & Histone $\mathrm{H} 2 \mathrm{~B}$ & 1.2791 \\
\hline & LmxM.30.3180 & Histone $\mathrm{H} 4$ & 1.1477 \\
\hline & LmxM.34.1310 & Histone H4 & 1.0938 \\
\hline & LmxM.19.0030 & Histone $\mathrm{H} 2 \mathrm{~B}$ & 1.0316 \\
\hline & LmxM.25.1470 & Cyclin & 2.3643 \\
\hline & LmxM.31.3320 & Cyclin 6, putative & 1.2431 \\
\hline & LmxM.28.1420 & DNA polymerase kappa, putative & 1.2764 \\
\hline & LmxM.28.1430 & DNA polymerase kappa, putative & 1.2214 \\
\hline & LmxM.34.1790 & DNA polymerase epsilon subunit B, putative & 1.1082 \\
\hline & LmxM.13.1630 & Mitochondrial DNA polymerase I protein D, putative & 1.0411 \\
\hline \multirow[t]{2}{*}{ Autophagy } & LmxM.27.0390 & Autophagy protein APG9, putative & 1.2217 \\
\hline & LmxM.23.1170 & Membrane-bound acid phosphatase 2 & 1.5534 \\
\hline \multirow[t]{13}{*}{ Cytoskeletal } & LmxM.08.1230 & $\beta$-tubulin & -1.1278 \\
\hline & LmxM.21.1860 & $\beta$-tubulin & -1.8051 \\
\hline & LmxM.32.0792 & $\beta$-tubulin & -1.9300 \\
\hline & LmxM.05.0040 & Paraflagellar rod component par4, putative & -1.2326 \\
\hline & LmxM.16.1430 & Paraflagellar rod protein 2 & -1.2388 \\
\hline & LmxM.09.1320 & Paraflagellar rod component, putative & -1.3933 \\
\hline & LmxM.08_29.1750 & Paraflagellar rod protein 1D, putative & -1.3995 \\
\hline & LmxM.36.4780 & Paraflagellar rod component, putative & -1.6234 \\
\hline & LmxM.16.1425 & Paraflagellar rod protein $2 \mathrm{C}$ & -1.9274 \\
\hline & LmxM.08_29.1760 & Paraflagellar rod protein $1 \mathrm{D}$, putative & -1.9294 \\
\hline & LmxM.07.0310 & Paraflagellar rod protein, putative & -2.0882 \\
\hline & LmxM.32.0610 & Paraflagellar rod component, putative & -2.3516 \\
\hline & LmxM.36.4230 & Paraflagellar rod component, putative & -3.0082 \\
\hline \multirow{6}{*}{$\begin{array}{l}\text { Transporters associated with anti- } \\
\text { mony response }\end{array}$} & LmxM.28.1930 & Zinc transporter 3, putative & 1.5220 \\
\hline & LmxM.30.3070 & Ferrous iron transport protein & 1.1716 \\
\hline & LmxM.23.0250 & ABC-thiol transporter & 1.1165 \\
\hline & LmxM.19.0180 & Mitogen-activated protein kinase 9, putative & 1.0732 \\
\hline & LmxM.13.0440 & Mitogen-activated protein kinase kinase 2 & 1.0641 \\
\hline & LmxM.30.1290 & Multidrug-resistance protein, copy 1-like protein & 1.1374 \\
\hline \multirow[t]{4}{*}{ H-locus } & LmxM.23.0230 & Hypothetical protein, conserved & 1.0664 \\
\hline & LmxM.23.0240 & Terbinafine resistance locus protein (yip1) & 1.3429 \\
\hline & LmxM.23.0250 & ABC-thiol transporter & 1.1165 \\
\hline & LmxM.23.0260 & Argininosuccinate synthase, putative & 1.2138 \\
\hline
\end{tabular}


Table 2 (continued)

\begin{tabular}{llll}
\hline Biological functions & Transcript & Product description & $\begin{array}{c}\text { Log fold- } \\
\text { change } \\
(\mathrm{R} / \mathrm{S})\end{array}$ \\
\hline Chaperones and stress proteins & LmxM.36.2030 & Chaperonin HSP60, mitochondrial precursor & 1.1311 \\
& LmxM.28.2780 & Heat-shock protein hsp70, putative & 2.6066 \\
& LmxM.32.0312 & Heat-shock protein 83-1 & 2.3109 \\
& LmxM.32.0316 & Heat-shock protein 83-1 & 2.1008 \\
& LmxM.32.0314 & Heat-shock protein 83-1 & 2.0412 \\
& LmxM.18.1370 & Heat-shock protein, putative & 1.3501 \\
& LmxM.28.2770 & Heat-shock protein hsp70, putative & 1.1175 \\
\hline
\end{tabular}

\section{Metabolism}

We then analysed and compared the expression of transcripts associated with the transport of sugar,

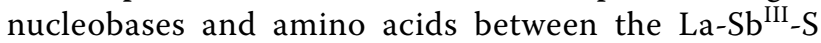
and $\mathrm{La}-\mathrm{Sb}^{\mathrm{III}}-\mathrm{R}$ lines. Most of the transcripts associated with these processes were downregulated in the resistant line, including six transcripts (LmxM.10.0350, LmxM.24.0360, LmxM.15.1230, LmxM.32.0290, LmxM.15.1240 and LmxM.30.0320) annotated as coding for a pteridine transporter, a UDP-galactose transporter, a nucleoside transporter 1 , a glucose transporter/membrane transporter D2, a nucleoside transporter 1 and an amino acid transporter, respectively.

Several genes encoding proteins associated with various metabolic pathways (glycolytic pathway, tricarboxylic acid cycle and proteolysis) were also differentially expressed between the sensitive and resistant lines. Downregulated genes in the $\mathrm{La}-\mathrm{Sb}^{\mathrm{III}}-\mathrm{R}$ line included LmxM.10.0510, encoding a glycerol3 -phosphate dehydrogenase [NAD+] enzyme that not only catalyses the interconversion of dihydroxyacetone phosphate and L-glycerol-3-phosphate during the glycolysis, but also is important in both lipid and carbohydrate metabolism; LmxM.08.1080, encoding cathepsin-L protease, which is putatively involved in proteolysis; and LmxM.29.1940, encoding succinylCoA:3-ketoacid-coenzyme, a transferase involved in the catabolism of ketone bodies. These three transcripts were approximately 1.1-fold, 2.2-fold and 1.5fold less abundant, respectively, in $\mathrm{La}-\mathrm{Sb}^{\mathrm{III}}-\mathrm{R}$ than in susceptible line La-Sb ${ }^{\text {III }}$-S.

Analysis of genes involved in the fatty acids pathway, which is associated with the intracellular amastigote stage and with promastigotes in culture, revealed upregulation in the $\mathrm{La}-\mathrm{Sb}^{\mathrm{III}}-\mathrm{R}$ line, of transcripts encoding a putative acetyl-CoA carboxylase (LmxM.30.2970), a putative acetyl-CoA synthetase (LmxM.23.0710), a mitochondrial proline dehydrogenase (LmxM.26.1610) and a 2-oxoglutarate dehydrogenase subunit (LmxM.27.0880), which is associated with the TCA cycle (Table 2).

\section{Cell cycle and autophagy}

Among the upregulated cell cycle-associated genes in the La-Sb ${ }^{\mathrm{III}}$ - $\mathrm{R}$ line, histone protein-coding genes were particularly enriched. Eleven transcripts (LmxM.10.0990, LmxM.10.0870, LmxM.36.0020, LmxM.19.0050, LmxM.30.3180, LmxM.34.1310, LmxM.19.0030, LmxM.20.0030, LmxM.07.0025, LmxM.25.0920 and LmxM.20.0050) encoding histonefamily or associated proteins, including histone 3 , histone 4 and histone $2 \mathrm{~B}$, were upregulated in the resistant line. Additionally, transcripts coding for proteins related to cellular replication were also upregulated in the $\mathrm{La}-\mathrm{Sb}^{\mathrm{III}}-\mathrm{R}$ line, including those encoding cyclin and cyclin 6 (LmxM.25.1470 and LmxM.31.3320), along with various polymerases (LmxM.28.1420, LmxM.28.1430, LmxM.34.1790 and LmxM.13.1630), such as DNA polymerase kappa, DNA polymerase epsilon subunit B and mitochondrial DNA polymerase I protein D.

We also observed upregulation of transcripts encoding autophagy protein APG9 (LmxM.27.0390) and membrane-bound acid phosphatase 2 (MBAP2) (LmxM.23.1170) in La-Sb ${ }^{\mathrm{III}}-\mathrm{R}$, both of which have been associated with the recycling of proteins under stress conditions and/or while undergoing a differentiation process (Table 2).

\section{Cytoskeleton}

Our analysis also identified differential expression of transcripts encoding proteins associated with the cytoskeleton between the $\mathrm{La}-\mathrm{Sb}^{\mathrm{III}}-\mathrm{R}$ and $\mathrm{La}-\mathrm{Sb}^{\mathrm{III}}-\mathrm{S}$ lines. We observed that three transcripts encoding $\beta$-tubulin and 10 transcripts encoding paraflagellar rod protein $1 \mathrm{D}$ were between 1.2-fold and 3.0-fold less 
abundant in the $\mathrm{La}-\mathrm{Sb}^{\mathrm{III}}-\mathrm{R}$ line than in susceptible line $\mathrm{La}-\mathrm{Sb}^{\mathrm{III}}-\mathrm{S}$ (Table 2).

\section{Antimonial resistance and stress response}

Some of the genes previously associated with antimonial resistance mechanisms in Leishmania species were shown to be differentially expressed between $\mathrm{La}-\mathrm{Sb}^{\mathrm{III}}-\mathrm{R}$ and $\mathrm{La}-\mathrm{Sb}^{\mathrm{III}}-\mathrm{S}$. In $\mathrm{La}-\mathrm{Sb}^{\mathrm{III}}-\mathrm{R}$, upregulated genes included LmxM.28.1930 (zinc transporter 3), LmxM.30.3070 (ferrous iron transport protein), LmxM.23.0250 (ABC-thiol transporter), LmxM.19.0180 and LmxM.13.0440 (mitogen-activated protein kinase 9/2) and LmxM.30.1290 [multidrug resistance protein, copy 1-like protein (MDR1)]. In addition, amplicons derived from the $\mathrm{H}$ locus were also upregulated in $\mathrm{La}-\mathrm{Sb}^{\mathrm{III}}-\mathrm{R}$, including transcripts coding for a hypothetical protein (LmxM.23.0230), HTB or terbinafine-resistance locus protein (Yip1) (LmxM.23.0240), an ABC-thiol transporter (MRPA) (LmxM.23.0250) and a putative argininosuccinate synthase (LmxM.23.0260).

Genes encoding several heat-shock proteins of different molecular masses were also upregulated in the $\mathrm{La}-\mathrm{Sb}^{\mathrm{III}}-\mathrm{R}$ line. Seven transcripts coding for heat-shock protein family members HSP70, HSP83-1 and HSP60 (LmxM.28.2780, LmxM.32.0312, LmxM.32.0316, LmxM.32.0314, LmxM.18.1370, LmxM.28.2770 and LmxM.36.2030) were approximately 2-fold more abundant in the resistant line (Table 2).

\section{Discussion}

RNA-seq technology was used to characterise alterations in gene expression of L. amazonensis resulting from experimental induction of $\mathrm{Sb}^{\mathrm{III}}$ resistance compared with an uninduced strain. Leishmania amazonensis is tremendously important in public health terms in Brazil and Colombia because of its association with $\mathrm{CL}$ and, more recently, VL in both humans and domestic animals (cats and dogs) $[34,35]$. This association not only indicates the severity of $L$. amazonensis infection, but also the possible emergence of a domestic cycle and an increased risk of disease transmission. Until now, different approaches have been used with the purpose of understanding the transcriptomic behaviour of different species of Leishmania against antimonials; however, to our knowledge, this is the first attempt to elucidate and demonstrate the global gene expression profile of L. amazonensis under $\mathrm{Sb}^{\mathrm{III}}$ pressure through RNA-seq. Herein, we identified a large number of genes showing differential expression between the sensitive and resistant lines (Fig. 2). Among these were transcripts encoding proteins associated with various biological processes, including adhesion, metabolism, cell cycle, autophagy, structural organisation and stress response (Fig. 3a).
Transcriptomic analysis of the different membranerelated proteins revealed differences between the $\mathrm{La}-\mathrm{Sb}^{\mathrm{III}}-\mathrm{S}$ and $\mathrm{La}-\mathrm{Sb}^{\mathrm{III}}-\mathrm{R}$ lines. Five transcripts encoding amastin proteins were overexpressed in $\mathrm{La}-\mathrm{Sb}^{\mathrm{III}}-\mathrm{R}$ (Table 2). The amastins are surface glycoproteins whose expression has been noted in other parasites such as Trypanosoma cruzi and Trypanosoma brucei (amastigotes and epimastigotes) [36, 37], as well as in two related insect parasites, Leptomonas seymouri and Crithidia spp. [38] and had been involved in host-parasite interactions, with roles in both infection and survival [38]. The upregulation of genes encoding amastin in our resistant line is consistent with a previous report [15], and although the relationship between this surface protein and antimonial resistance has not previously been demonstrated in Leishmania, our results suggest that overexpression of genes encoding amastin could increase the resistance of the parasite to the cellular stresses elicited by $\mathrm{Sb}^{\mathrm{III}}$. In contrast, other surface protein-encoding genes, including those coding for PSA, proteophosphoglycan ppg3/ppg1, LPG, surface membrane protein gp46-like protein and major surface protease gp63/leishmanolysin, appeared to be downregulated in the resistant line (Fig. 3a, Table 2). Of these, only GP63 has previously been identified on the surface of Leishmania and other trypanosomatid species [39]. The downregulation of these genes under our study conditions suggests that $L$. amazonensis reduces the expression of some genes involved in virulence, interaction and survival in macrophages that are not necessary for survival under drug pressure. Future studies are needed in insect cell lines/macrophages to determine whether these genes are also downregulated during the Leishmania infection process.

On the other hand, most trypanosomatid species predominantly utilise glycolysis, amino acid metabolism and the fatty acid pathway (promastigotes maintained in culture) for energy generation [40-42]. Previous studies in Leishmania species have suggested that antimonials not only alter energetic metabolism by inhibiting glycolysis and fatty acids oxidation [10], but also cause changes in the transport of nutrients through the plasma membrane, as has been observed in Sb-resistant Leishmania strains [43]. Although we did not observe large variations in the expression of genes associated with metabolism between the sensitive and resistant lines, changes in the expression of genes encoding proteins associated with the glycolytic pathway or encoding glycolytic enzymes essentials in both lipid and carbohydrate metabolism and ATP production (downregulation of glucose transporter/membrane transporter D2 and glycerol-3-phosphate dehydrogenase $[\mathrm{NAD}+]$ ) were consistent with previous reports in Sb-resistant L. amazonensis [44, 45] (Table 2). Additionally, GO analysis revealed a strong 
downregulation of genes involved in carbohydrate transport (Fig. 3b), which suggests decreased formation of reactive oxygen species as a result of reduced glucose uptake, thereby aiding survival in the oxidative environment triggered by the drug [45].

In the present study, we observed the upregulation of 11 transcripts in the $\mathrm{Sb}^{\mathrm{III}}$-resistant line encoding histone proteins, namely H2B, H3 and H4 (Table 2). These proteins are associated with various biological processes in Leishmania and other trypanosomatids (T. brucei and T. cruzi) and are closely associated with transcription, DNA replication, recombination and repair [46-49], and likewise have been associated with antimony resistance in Leishmania parasites [15, 50]. GO analysis also confirmed a strong upregulation of genes involved in the regulation of the cell cycle (Fig. 3b), which agrees with data presented in a previous report [50]. These results reinforce the previously-noted association of histone proteins with resistance to antimonials found mainly in $L$. donovani $[18,50]$, and suggest similar behaviour in New World Leishmania species such as L. amazonensis.

Previous studies showed that the recycling of proteins by autophagic mechanisms is associated with metabolism in cells that are undergoing a differentiation process (metacyclogenesis) and/or under stress conditions [51, 52]. Our study identified upregulation of mRNA from chromosome 27 corresponding to the putative APG9 protein (Table 2), which is involved in autophagy and cytoplasm-to-vacuole transport (Cvt) vesicle formation, in the La-Sb ${ }^{\mathrm{III}}-\mathrm{R}$ line. This suggests that in the presence of $\mathrm{Sb}^{\mathrm{III}}, L$. amazonensis activates genes that induce autophagy, either as a survival strategy or as a form of cell death. This has also been observed in other parasites such as T. brucei, T. cruzi, Leishmania donovani, Toxoplasma gondii and Plasmodium falciparum, which activate different autophagy proteins (ATG3, ATG5, ATG7, ATG24 and PI3K) during nutrient starvation and under drug-induced stress as a mechanism of programmed cell death [53-55].

Another factor that may trigger protein recycling is purine starvation. Leishmania, Trypanosoma and Toxoplasma do not synthesise purines de novo and must scavenge them from the environment [56-58]. In response to this starvation, alterations are made to different metabolic processes, such as upregulation of purine salvage machinery. One of the most upregulated genes in purinestarved Leishmania parasites codes for membrane-bound acid phosphatase (MBAP2), which has a role in endosomal trafficking [52]. In the present study, we observed upregulation of the MBAP2 transcript in the La-Sb ${ }^{\mathrm{III}}-\mathrm{R}$ line (Table 2), suggesting an increase in lysosome-related recycling processes, as has been noted in L. major [52].

Additionally, studies have demonstrated that drug pressure produces changes at the cytoskeletal level $(\alpha-$ and $\beta$-tubulin proteins), provoking several mutations related to drug resistance. This phenomenon has been identified in Leishmania species, including L. tarentolae [59], and has also been present in the homologous genes from T. cruzi, T. brucei and T. evansi $[18,60]$. In the present study, we observed downregulation of transcripts encoding $\beta$-tubulin and paraflagellar rod protein $1 \mathrm{D}$ in the $\mathrm{Sb}^{\mathrm{III}}$-resistant line (Table 2), as was recently observed in a resistant strain of L. braziliensis [61]. These results suggest that the development of antimony resistance may cause changes in cytoskeleton proteins as well.

Finally, several studies support the existence of a variety of resistance mechanisms in Leishmania parasites. One known mechanism of antimony resistance involves the reduction of drug accumulation by either reduced uptake or increased efflux through different membrane transporters, the most studied of which belongs to the ATP-binding cassette $(\mathrm{ABC})$ protein superfamily [16, 62]. These protein transporters have been identified in other parasites including T. brucei and T. cruzi, and as in Leishmania species, their overexpression is implicated in resistance to different drugs [63-65]. In the present transcriptomic analysis, we observed upregulation of different transcripts encoding protein transporters in the La-Sb ${ }^{\text {III- }}$ R line (Table 2), all of which have previously been implicated in resistance to antimonials in other Leishmania species $[15,16]$. These transporters included zinc transporter 3, ferrous iron transport protein and membrane transporters of the ABC superfamily (MDR1 and MRPA).

The L. amazonensis mdr1 gene, which has demonstrated to be 91 and $78 \%$ identical to the closely related ldmdr1 gene in L. donovani and lemdr1 gene in L. enriettii, respectively [66, 67], has been shown to be overexpressed in amphotericin B- and Sb-resistant strains of L. donovani [68-70], in a melarsoprol-resistant strain of T. brucei $[71,72]$ and in benznidazole-resistant epimastigotes of T. cruzi $[64,65]$. Otherwise the gene encoding MRPA, which is one of three genes related to drug resistance identified within the $\mathrm{H}$ locus and which is amplified in extrachromosomal circles of DNA, was overexpressed in a number of Leishmania strains selected for resistance to $\mathrm{Sb}^{\mathrm{III}}, \mathrm{Sb}^{\mathrm{V}}$ or the related metal $[15,73-76]$. Additionally, overexpression of MRPA has been reported to decrease the influx of antimony rather than increase efflux [10]. The overexpression of genes that encode the MDR1 and MRPA transporters in our experimentally-induced $\mathrm{Sb}^{\mathrm{III}}$-resistant $L$. amazonensis strain suggests that active efflux/influx of $\mathrm{Sb}^{\mathrm{III}}$ is a mechanism used by this species to survive in the presence of drug pressure, supporting previous reports in other species.

We also observed upregulation of genes coding for mitogen-activated protein kinases (MAPKs), which have 
been associated with important cell processes such as proliferation, differentiation, cell shape, stress response, apoptosis and immune evasion in trypanosomatids [77, 78], and putatively with antimony resistance in Leishmania parasites [79]. Of the 17 MAPKs and MAPK-like kinases identified in Leishmania [80], only MAPK1 has previously been associated with antimony resistance. However, expression of the MAPK1 gene in resistant L. donovani appears variable, with some reports showing consistent upregulation in resistant isolates [50] and others showing downregulation in antimony-resistant field isolates $[79,81]$. Although genes coding for MAPK2 and MAPK9 were upregulated in our resistant line, neither of these proteins have previously been reported in $\mathrm{Sb}^{\mathrm{III}}$-resistant strains, suggesting that their association with antimony resistance should be further studied.

Other genes overexpressed in the resistant L. amazonensis line were those encoding heat-shock proteins (HSPs). HSPs are a family of proteins whose function is to protect the cell from toxic external stimuli. Various in vitro studies have recorded the overexpression of different HSPs in drug-resistant Leishmania strains [15, 18, 82, 83]. However, although HSPs are the most abundant proteins in T. cruzi [84], their role in drug resistance remains unclear [85]. Of the HSPs identified in Leishmania parasites, HSP83 and HSP70 are involved in the activation of programmed cell death mediated by drugs, as they interfere with the mitochondrial membrane potential as has been observed in strains of $L$. donovani $[83,86]$. In the present study, we observed the overexpression of transcripts encoding HSP70, HSP83 and HSP60 in the La-Sb ${ }^{\mathrm{III}}$-R line (Table 2). This supports previous findings [61] and reinforces the role of these proteins in resistance to antimony, both in Old and New World Leishmania species.

\section{Conclusions}

The transcriptomic analysis conducted in this study identified several transcripts that were differentially abundant between the antimony-resistant and -sensitive lines, several of which have previously been reported as potential therapeutic targets in Old World species as well as some New World species, including L. braziliensis, L. guyanensis and L. panamensis. Thus, we conclude that next-generation sequencing technologies are, and will continue to be, the gold standard techniques for understanding transcriptomic behaviour of a large number of organisms, increasing our knowledge of poorly understood species. Finally, although various studies propose intracellular amastigotes as the gold standard for in vitro Leishmania drug discovery research and evaluation of resistance [87, 88], we focused our molecular analysis on the promastigote stage for several reasons: the amastigote model is (i) time-consuming, (ii) laborious, (iii) difficult to manipulate in terms of inducing $\mathrm{Sb}^{\mathrm{III}}$-resistance $[89,90]$, and (iv) difficult to scale, thereby limiting its use in high-throughput screening approaches [91]. However, considering that the amastigote stage is the infectious form in the host, and that some of the genes with differential expression found in this study have been previously described by other researches using axenic amastigotes [22, 26], the results obtained here can be used in the future to guide targeted studies in this parasite infective stage. Future studies need to be conducted to validate the transcriptomic responses herein described.

\section{Additional files}

Additional file 1: Figure S1. Percent viability ( $Y$-axis) of L. amazonensis promastigotes treated for $72 \mathrm{~h}$ with different concentrations of Sb $b^{\text {III }}(1.0$ to $128.5 \mu \mathrm{g} / \mathrm{ml}$ ), represented as [Sb"l'] $\log _{10}$ (X-axis). The arrows show the IC50 reached by each line.

Additional file 2: Table S1. List of differentially expressed genes between La-SbIII-S and La-SbIII-R lines with a fold-change $\geq 2$.

\section{Abbreviations}

La: Leishmania amazonensis; Sb"l': trivalent sodium stibogluconate; DEG: differentially expressed gene; HSP: heat-shock protein; RNA-seq: ribonucleic acid sequencing.

\section{Acknowledgements}

We thank Hideo Imamura and Jean Claude Dujardin from the Institute of Tropical Medicine in Belgium for their assistance in the analyses. We thank Maria Adelaida Gomez from CIDEIM, Colombia for donating the Sb'II. We also thank Tamsin Sheen PhD, from Edanz Group (www.edanzediting.com/ac) for editing a draft of this manuscript.

\section{Authors' contributions}

LHP conceived and designed the study, analysed and interpreted the data and prepared the manuscript. CM critically revised the manuscript and made important suggestions. JDR conceived and designed the study and revised the manuscript. All authors read and approved the final manuscript.

\section{Funding}

This work was funded by the Dirección de Investigación e Innovación of the Universidad del Rosario. LHP is funded by the Colombian Science, Technology, Science and Innovation Department (Colciencias) call for PhD training in Colombia, within the framework of the National Programme for Promoting Research Training (sponsorship calls 647)

\section{Availability of data and materials}

Data supporting the conclusions of this article are included within the article and its additional files. The dataset generated during the present study was deposited at DDBJ/ENA/GenBank under the accession number PRJEB31417.

\section{Ethics approval and consent to participate}

This project was approved by the Ethics Committee of the Universidad de Antioquia (number VRI3445/2010). Written informed consent was obtained from the patient from which the strain was isolated.

\section{Consent for publication}

Not applicable.

\section{Competing interests}

The authors declare that they have no competing interests. 


\section{Author details}

${ }^{1}$ Grupo de Investigaciones Microbiológicas-UR (GIMUR), Programa de Biología, Facultad de Ciencias Naturales y Matemáticas, Universidad del Rosario, Bogotá, Colombia. ${ }^{2}$ Programa de Estudio y Control de Enfermedades Tropicales (PECET), Facultad de Medicina, Universidad de Antioquia, Medellín, Colombia.

Received: 15 March 2019 Accepted: 6 July 2019

Published online: 12 July 2019

\section{References}

1. Bates PA. Transmission of Leishmania metacyclic promastigotes by phlebotomine sand flies. Int J Parasitol. 2007;37:1097-106.

2. Paranaiba LF, Pinheiro LJ, Torrecilhas AC, Macedo DH, Menezes-Neto A, Tafuri WL, et al. Leishmania enriettii (Muniz \& Medina, 1948): a highly diverse parasite is here to stay. PLoS Pathog. 2017;13:e1006303.

3. Silveira FT, Lainson R, De Castro Gomes CM, Laurenti MD, Corbett CE. Immunopathogenic competences of Leishmania (V.) braziliensis and $L$. (L.) amazonensis in American cutaneous leishmaniasis. Parasite Immunol. 2009;31:423-31.

4. Camara Coelho LI, Paes M, Guerra JA, Barbosa M, Coelho C, Lima B, et al. Characterization of Leishmania spp. causing cutaneous leishmaniasis in Manaus, Amazonas, Brazil. Parasitol Res. 2011;108:671-7.

5. Ramirez JD, Hernandez C, Leon CM, Ayala MS, Florez C, Gonzalez C. Taxonomy, diversity, temporal and geographical distribution of cutaneous leishmaniasis in Colombia: a retrospective study. Sci Rep. 2016;6:28266.

6. Sanches LD, Martini CC, Nakamura AA, Santiago ME, Dolabela de Lima B, Lima VM. Natural canine infection by Leishmania infantum and Leishmania amazonensis and their implications for disease control. Rev Bras Parasitol Vet. 2016;25:465-9.

7. Carvalho FS, Wenceslau AA, Albuquerque GR, Munhoz AD, Gross E, Carneiro PL, et al. Leishmania (Viannia) braziliensis in dogs in Brazil: epidemiology, co-infection, and clinical aspects. Genet Mol Res. 2015;14:12062-73.

8. Tolezano JE, Uliana SR, Taniguchi HH, Araujo MF, Barbosa JA, Barbosa JE, et al. The first records of Leishmania (Leishmania) amazonensis in dogs (Canis familiaris) diagnosed clinically as having canine visceral leishmaniasis from Aracatuba County, Sao Paulo State, Brazil. Vet Parasitol. 2007;149:280-4.

9. Aleixo JA, Nascimento ET, Monteiro GR, Fernandes MZ, Ramos AM, Wilson $M E$, et al. Atypical American visceral leishmaniasis caused by disseminated Leishmania amazonensis infection presenting with hepatitis and adenopathy. Trans R Soc Trop Med Hyg. 2006;100:79-82.

10. Ashutosh, Sundar S, Goyal N. Molecular mechanisms of antimony resistance in Leishmania. J Med Microbiol. 2007;56:143-53.

11. de Macedo-Silva ST, Urbina JA, de Souza W, Rodrigues JC. In vitro activity of the antifungal azoles itraconazole and posaconazole against Leishmania amazonensis. PLoS ONE. 2013;8:e83247.

12. Ponte-Sucre A, Gamarro F, Dujardin JC, Barrett MP, Lopez-Velez R, GarciaHernandez R, et al. Drug resistance and treatment failure in leishmaniasis: a 21st century challenge. PLoS Negl Trop Dis. 2017;11:e0006052.

13. Mukherjee A, Boisvert S, Monte-Neto RL, Coelho AC, Raymond F, Mukhopadhyay $R$, et al. Telomeric gene deletion and intrachromosomal amplification in antimony-resistant Leishmania. Mol Microbiol. 2013;88:189-202.

14. Cuypers B, Berg M, Imamura H, Dumetz F, De Muylder G, Domagalska MA et al. Integrated genomic and metabolomic profiling of ISC1, an emerging Leishmania donovani population in the Indian subcontinent. Infect Genet Evol. 2018;62:170-8.

15. Rastrojo A, Garcia-Hernandez R, Vargas P, Camacho E, Corvo L, Imamura $\mathrm{H}$, et al. Genomic and transcriptomic alterations in Leishmania donovani lines experimentally resistant to antileishmanial drugs. Int J Parasitol Drugs Drug Resist. 2018;8:246-64.

16. Laffitte MN, Leprohon P, Papadopoulou B, Ouellette M. Plasticity of the Leishmania genome leading to gene copy number variations and drug resistance. F1000Res. 2016;5:2350.

17. Brotherton MC, Bourassa S, Leprohon P, Legare D, Poirier GG, Droit A, et al. Proteomic and genomic analyses of antimony resistant Leishmania infantum mutant. PLoS ONE. 2013;8:e81899.
18. Biyani N, Singh AK, Mandal S, Chawla B, Madhubala R. Differential expression of proteins in antimony-susceptible and -resistant isolates of Leishmania donovani. Mol Biochem Parasitol. 2011;179:91-9.

19. Dillon LA, Okrah K, Hughitt VK, Suresh R, Li Y, Fernandes MC, et al. Transcriptomic profiling of gene expression and RNA processing during Leishmania major differentiation. Nucleic Acids Res. 2015;43:6799-813.

20. Fiebig M, Kelly S, Gluenz E. Comparative life cycle transcriptomics revises Leishmania mexicana genome annotation and links a chromosome duplication with parasitism of vertebrates. PLoS Pathog. 2015;11:e1005186.

21. Fernandes MC, Dillon LA, Belew AT, Bravo HC, Mosser DM, El-Sayed NM. Dual transcriptome profiling of Leishmania-infected human macrophages reveals distinct reprogramming signatures. MBio. 2016;7:e00027-16.

22. Aoki J, Muxel SM, Zampieri RA, Laranjeira-Silva MF, Muller KE, Nerland AH, et al. RNA-seq transcriptional profiling of Leishmania amazonensis reveals an arginase-dependent gene expression regulation. PLoS Negl Trop Dis. 2017;11:e0006026.

23. Leprohon P, Fernandez-Prada C, Gazanion E, Monte-Neto R, Ouellette M. Drug resistance analysis by next generation sequencing in Leishmania. Int J Parasitol Drugs Drug Resist. 2015;5:26-35.

24. Patino LH, Ramirez JD. RNA-seq in kinetoplastids: a powerful tool for the understanding of the biology and host-pathogen interactions. Infect Genet Evol. 2017;49:273-82.

25. Vacchina P, Norris-Mullins B, Abengozar MA, Viamontes CG, Sarro J, Stephens MT, et al. Genomic appraisal of the multifactorial basis for in vitro acquisition of miltefosine resistance in Leishmania donovani. Antimicrob Agents Chemother. 2016;60:4089-100.

26. Aoki Jl, Muxel SM, Zampieri RA, Acuna SM, Fernandes JCR, Vanderlinde $\mathrm{RH}$, et al. L-arginine availability and arginase activity: characterization of amino acid permease 3 in Leishmania amazonensis. PLoS Negl Trop Dis. 2017;11:e0006025.

27. Christensen SM, Dillon LA, Carvalho LP, Passos S, Novais FO, Hughitt VK, et al. Meta-transcriptome profiling of the human-Leishmania braziliensis cutaneous lesion. PLoS Negl Trop Dis. 2016;10:e0004992.

28. Ouellette M, Fase-Fowler F, Borst P. The amplified H circle of methotrexate-resistant leishmania tarentolae contains a novel P-glycoprotein gene. EMBO J. 1990;9:1027-33.

29. Paris C, Bertoglio J, Breard J. Lysosomal and mitochondrial pathways in miltefosine-induced apoptosis in U937 cells. Apoptosis. 2007;12:1257-67.

30. Ramirez JD, Herrera C, Bogota Y, Duque MC, Suarez-Rivillas A, Guhl F. Validation of a Poisson-distributed limiting dilution assay (LDA) for a rapid and accurate resolution of multiclonal infections in natural Trypanosoma cruzi populations. J Microbiol Methods. 2013;92:220-5.

31. Downing T, Imamura H, Decuypere S, Clark TG, Coombs GH, Cotton JA, et al. Whole genome sequencing of multiple Leishmania donovani clinical isolates provides insights into population structure and mechanisms of drug resistance. Genome Res. 2011;21:2143-56.

32. Imamura H, Downing T, Van den Broeck F, Sanders MJ, Rijal S, Sundar S, et al. Evolutionary genomics of epidemic visceral leishmaniasis in the Indian subcontinent. Elife. 2016;5:e12613.

33. Supek F, Bosnjak M, Skunca N, Smuc T. REVIGO summarizes and visualizes long lists of gene ontology terms. PLoS ONE. 2011;6:e21800.

34. Valdivia HO, Almeida LV, Roatt BM, Reis-Cunha JL, Pereira AA, Gontijo C, et al. Comparative genomics of canine-isolated Leishmania (Leishmania) amazonensis from an endemic focus of visceral leishmaniasis in Governador Valadares, southeastern Brazil. Sci Rep. 2017;7:40804.

35. de Souza CSF, Calabrese KS, Abreu-Silva AL, Carvalho LOP, Cardoso FO, Dorval M, et al. Leishmania amazonensis isolated from human visceral leishmaniasis: histopathological analysis and parasitological burden in different inbred mice. Histol Histopathol. 2018;33:705-16.

36. Perez-Diaz L, Silva TC, Teixeira SM. Involvement of an RNA binding protein containing Alba domain in the stage-specific regulation of beta-amastin expression in Trypanosoma cruzi. Mol Biochem Parasitol. 2017;211:1-8.

37. Cruz MC, Souza-Melo N, da Silva CV, Darocha WD, Bahia D, Araujo PR, et al. Trypanosoma cruzi: role of delta-amastin on extracellular amastigote cell invasion and differentiation. PLOS ONE. 2012;7:e51804.

38. Jackson AP. The evolution of amastin surface glycoproteins in trypanosomatid parasites. Mol Biol Evol. 2010;27:33-45. 
39. Pech-Canul AC, Monteon V, Solis-Oviedo RL. A brief view of the surface membrane proteins from Trypanosoma cruzi. J Parasitol Res. 2017;2017:3751403

40. Maugeri DA, Cannata JJ, Cazzulo JJ. Glucose metabolism in Trypanosoma cruzi. Essays Biochem. 2011;51:15-30.

41. Hellemond JJ, Bakker BM, Tielens AG. Energy metabolism and its compartmentation in Trypanosoma brucei. Adv Microb Physiol. 2005;50:199-226.

42. Bringaud F, Riviere L, Coustou V. Energy metabolism of trypanosomatids: adaptation to available carbon sources. Mol Biochem Parasitol. 2006;149:1-9.

43. Frezard F, Monte-Neto R, Reis PG. Antimony transport mechanisms in resistant leishmania parasites. Biophys Rev. 2014;6:119-32.

44. do Monte-Neto RL, Coelho AC, Raymond F, Legare D, Corbeil J, Melo MN, et al. Gene expression profiling and molecular characterization of antimony resistance in Leishmania amazonensis. PLoS Negl Trop Dis. 2011;5:e1167.

45. Machuca C, Rodriguez A, Herrera M, Silva S, Ponte-Sucre A. Leishmania amazonensis: metabolic adaptations induced by resistance to an $A B C$ transporter blocker. Exp Parasitol. 2006:114:1-9.

46. Soto M, Iborra S, Quijada L, Folgueira C, Alonso C, Requena JM. Cellcycle-dependent translation of histone mRNAs is the key control point for regulation of histone biosynthesis in Leishmania infantum. Biochem J. 2004:379:617-25.

47. Figueiredo LM, Cross GA, Janzen CJ. Epigenetic regulation in African trypanosomes: a new kid on the block. Nat Rev Microbiol. 2009;7:504-13.

48. Glover L, Horn D. Trypanosomal histone gammaH2A and the DNA damage response. Mol Biochem Parasitol. 2012;183:78-83.

49. Leandro de Jesus TC, Calderano SG, Vitorino FN, Llanos RP, Lopes MC, de Araujo CB, et al. Quantitative proteomic analysis of replicative and nonreplicative forms reveals important insights into chromatin biology of Trypanosoma cruzi. Mol Cell Proteomics. 2017;16:23-38.

50. Singh R, Kumar D, Duncan RC, Nakhasi HL, Salotra P. Overexpression of histone H2A modulates drug susceptibility in Leishmania parasites. Int J Antimicrob Agents. 2010;36:50-7.

51. Levine B, Klionsky DJ. Development by self-digestion: molecular mechanisms and biological functions of autophagy. Dev Cell. 2004;6:463-77.

52. Inbar E, Hughitt VK, Dillon LA, Ghosh K, El-Sayed NM, Sacks DL. The transcriptome of Leishmania major developmental stages in their natural sand fly vector. MBio. 2017;8:e00029-17.

53. Li FJ, He CY. Autophagy in protozoan parasites: Trypanosoma brucei as a model. Future Microbiol. 2017:12:1337-40.

54. Li FJ, Shen Q, Wang C, Sun Y, Yuan AY, He CY. A role of autophagy in Trypanosoma brucei cell death. Cell Microbiol. 2012;14:1242-56.

55. Sinai AP, Roepe PD. Autophagy in Apicomplexa: a life sustaining death mechanism? Trends Parasitol. 2012;28:358-64.

56. Carter NS, Yates P, Arendt CS, Boitz JM, Ullman B. Purine and pyrimidine metabolism in Leishmania. Adv Exp Med Biol. 2008;625:141-54.

57. Li Q, Leija C, Rijo-Ferreira F, Chen J, Cestari I, Stuart K, et al. GMP synthase is essential for viability and infectivity of Trypanosoma brucei despite a redundant purine salvage pathway. Mol Microbiol. 2015;97:1006-20.

58. Gherardi A, Sarciron ME, Petavy AF, Peyron F. Purine pathway enzymes in a cyst forming strain of Toxoplasma gondii. Life Sci. 1999;65:1733-8.

59. Luis L, Serrano ML, Hidalgo M, Mendoza-Leon A. Comparative analyses of the beta-tubulin gene and molecular modeling reveal molecular insight into the colchicine resistance in kinetoplastids organisms. Biomed Res Int. 2013;2013:843748.

60. Li SQ, Fung MC, Reid SA, Inoue N, Lun ZR. Immunization with recombinant beta-tubulin from Trypanosoma evansi induced protection against $T$. evansi, T. equiperdum and T. b. brucei infection in mice. Parasite Immunol. 2007;29:191-9.

61. Matrangolo FS, Liarte DB, Andrade LC, de Melo MF, Andrade JM, Ferreira RF, et al. Comparative proteomic analysis of antimony-resistant and -susceptible Leishmania braziliensis and Leishmania infantum chagasi lines. Mol Biochem Parasitol. 2013;190:63-75.

62. Croft SL, Sundar S, Fairlamb AH. Drug resistance in leishmaniasis. Clin Microbiol Rev. 2006;19:111-26.

63. Shahi SK, Krauth-Siegel RL, Clayton CE. Overexpression of the putative thiol conjugate transporter TbMRPA causes melarsoprol resistance in Trypanosoma brucei. Mol Microbiol. 2002;43:1129-38.
64. Campos MC, Castro-Pinto DB, Ribeiro GA, Berredo-Pinho MM, Gomes $\mathrm{LH}$, da Silva Bellieny MS, et al. P-glycoprotein efflux pump plays an important role in Trypanosoma cruzi drug resistance. Parasitol Res. 2013;112:2341-51.

65. da Costa KM, Valente RC, Salustiano EJ, Gentile LB, Freire-de-Lima L, Mendonca-Previato $L$, et al. Functional characterization of $A B C C$ proteins from Trypanosoma cruzi and their involvement with thiol transport. Front Microbiol. 2018;9:205

66. Katakura K, Iwanami M, Ohtomo H, Fujise H, Hashiguchi Y. Structural and functional analysis of the LaMDR1 multidrug resistance gene in Leishmania amazonensis. Biochem Biophys Res Commun. 1999;255:289-94.

67. Legare D, Richard D, Mukhopadhyay R, Stierhof YD, Rosen BP, Haimeur A, et al. The Leishmania ATP-binding cassette protein PGPA is an intracellular metal-thiol transporter ATPase. J Biol Chem. 2001;276:26301-7.

68. Purkait B, Kumar A, Nandi N, Sardar AH, Das S, Kumar S, et al. Mechanism of amphotericin B resistance in clinical isolates of Leishmania donovani. Antimicrob Agents Chemother. 2012;56:1031-41.

69. Mukherjee B, Mukhopadhyay R, Bannerjee B, Chowdhury S, Mukherjee S, Naskar K, et al. Antimony-resistant but not antimony-sensitive Leishmania donovani up-regulates host IL-10 to overexpress multidrug-resistant protein 1. Proc Natl Acad Sci USA. 2013;110:E575-82.

70. Bhandari V, Sundar S, Dujardin JC, Salotra P. Elucidation of cellular mechanisms involved in experimental paromomycin resistance in Leishmania donovani. Antimicrob Agents Chemother. 2014;58:2580-5.

71. Alibu VP, Richter C, Voncken F, Marti G, Shahi S, Renggli CK, et al. The role of Trypanosoma brucei MRPA in melarsoprol susceptibility. Mol Biochem Parasitol. 2006:146:38-44.

72. Alibu VP, Daunes S, D'Silva C. N-benzyloxycarbonyl-S-(2,4-dinitrophenyl) glutathione dibutyl diester is inhibitory to melarsoprol resistant cell lines overexpressing the T. brucei MRPA transporter. Bioorg Med Chem Lett. 2013;23:4351-3.

73. Ouellette M, Drummelsmith J, Papadopoulou B. Leishmaniasis: drugs in the clinic, resistance and new developments. Drug Resist Updat. 2004; 7:257-66.

74. Oliaee RT, Sharifi I, Afgar A, Kareshk AT, Asadi A, Heshmatkhah A, et al. Unresponsiveness to meglumine antimoniate in anthroponotic cutaneous leishmaniasis field isolates: analysis of resistance biomarkers by gene expression profiling. Trop Med Int Health. 2018;23:622-33.

75. Dias FC, Ruiz JC, Lopes WC, Squina FM, Renzi A, Cruz AK, et al. Organization of H locus conserved repeats in Leishmania (Viannia) braziliensis correlates with lack of gene amplification and drug resistance. Parasitol Res. 2007;101:667-76.

76. Mukherjee A, Padmanabhan PK, Singh S, Roy G, Girard I, Chatterjee M, et al. Role of ABC transporter MRPA, gamma-glutamylcysteine synthetase and ornithine decarboxylase in natural antimony-resistant isolates of Leishmania donovani. J Antimicrob Chemother. 2007:59:204-11.

77. Chen Z, Gibson TB, Robinson F, Silvestro L, Pearson G, Xu B, et al. MAP kinases. Chem Rev. 2001;101:2449-76.

78. Soares-Silva M, Diniz FF, Gomes GN, Bahia D. The mitogen-activated protein kinase (MAPK) pathway: role in immune evasion by trypanosomatids Front Microbiol. 2016:7:183.

79. Garg M, Goyal N. MAPK1 of Leishmania donovani modulates antimony susceptibility by downregulating P-glycoprotein efflux pumps. Antimicrob Agents Chemother. 2015;59:3853-63.

80. Kuhn D, Wiese M. LmxPK4, a mitogen-activated protein kinase kinase homologue of Leishmania mexicana with a potential role in parasite differentiation. Mol Microbiol. 2005;56:1169-82.

81. Ashutosh, Garg M, Sundar S, Duncan R, Nakhasi HL, Goyal N. Downregulation of mitogen-activated protein kinase 1 of Leishmania donovani field isolates is associated with antimony resistance. Antimicrob Agents Chemother. 2012;56:518-25.

82. Brochu C, Haimeur A, Ouellette M. The heat shock protein HSP70 and heat shock cognate protein HSC70 contribute to antimony tolerance in the protozoan parasite Leishmania. Cell Stress Chaperones. 2004; 9:294-303.

83. Vergnes B, Gourbal B, Girard I, Sundar S, Drummelsmith J, Ouellette M. A proteomics screen implicates HSP83 and a small kinetoplastid calpainrelated protein in drug resistance in Leishmania donovani clinical field isolates by modulating drug-induced programmed cell death. Mol Cell Proteomics. 2007;6:88-101. 
84. Parodi-Talice A, Duran R, Arrambide N, Prieto V, Pineyro MD, Pritsch O, et al. Proteome analysis of the causative agent of Chagas disease: Trypanosoma cruzi. Int J Parasitol. 2004;34:881-6.

85. Murta SM, Nogueira FB, Dos Santos PF, Campos FM, Volpe C, Liarte DB, et al. Differential gene expression in Trypanosoma cruzi populations susceptible and resistant to benznidazole. Acta Trop. 2008;107:59-65.

86. Kumar A, Sisodia B, Misra P, Sundar S, Shasany AK, Dube A. Proteome mapping of overexpressed membrane-enriched and cytosolic proteins in sodium antimony gluconate (SAG) resistant clinical isolate of Leishmania donovani. Br J Clin Pharmacol. 2010;70:609-17.

87. Vermeersch M, da Luz RI, Tote K, Timmermans JP, Cos P, Maes L. In vitro susceptibilities of Leishmania donovani promastigote and amastigote stages to antileishmanial reference drugs: practical relevance of stagespecific differences. Antimicrob Agents Chemother. 2009;53:3855-9.

88. Teixeira MC, de Jesus Santos R, Sampaio RB, Pontes-de-Carvalho L, dosSantos WL. A simple and reproducible method to obtain large numbers of axenic amastigotes of different Leishmania species. Parasitol Res. 2002;88:963-8.
89. Hendrickx S, Boulet G, Mondelaers A, Dujardin JC, Rijal S, Lachaud L, et al. Experimental selection of paromomycin and miltefosine resistance in intracellular amastigotes of Leishmania donovani and L. infantum. Parasitol Res. 2014;113:1875-81.

90. Shaw CD, Lonchamp J, Downing T, Imamura H, Freeman TM, Cotton JA, et al. In vitro selection of miltefosine resistance in promastigotes of Leishmania donovani from Nepal: genomic and metabolomic characterization. Mol Microbiol. 2016;99:1134-48.

91. Ashutosh, Gupta S, Ramesh, Sundar S, Goyal N. Use of Leishmania donovani field isolates expressing the luciferase reporter gene in in vitro drug screening. Antimicrob Agents Chemother. 2005;49:3776-83.

\section{Publisher's Note}

Springer Nature remains neutral with regard to jurisdictional claims in published maps and institutional affiliations.
Ready to submit your research? Choose BMC and benefit from:

- fast, convenient online submission

- thorough peer review by experienced researchers in your field

- rapid publication on acceptance

- support for research data, including large and complex data types

- gold Open Access which fosters wider collaboration and increased citations

- maximum visibility for your research: over $100 \mathrm{M}$ website views per year

At BMC, research is always in progress.

Learn more biomedcentral.com/submissions 